\title{
Exhaustion, Non-exhaustion and Implied Licence
}

\author{
Poorna Mysoor
}

Published online: 19 June 2018

(C) The Author(s) 2018

\begin{abstract}
This article explores how exhaustion and non-exhaustion of certain rights can be more coherently explained using the common law doctrine of implied licence. Exhaustion, as the name suggests, only focuses on the effect of the first sale or other transfer of ownership of the original or the copy of the work on the copyright owner, namely the consumption of the distribution right. Although the consumption is distinctly for the benefit of the transferee of the original or the copy, the provisions in the directives on exhaustion do not reveal the effect of exhaustion on these transferees, nor the policy justifications that drive such consumption. These provisions only provide simplistically that the distribution of goods exhausts, but the provision of services does not. This leads to certain misconceptions that exhaustion cannot occur if the copy of the work is not in a tangible medium and that for all provision of services authorisation is required. The doctrine of implied licence can help address these concerns. Instead of regarding exhaustion as a statutory phenomenon, reframing it as a licence implied by statute changes the focus from the right lost by the copyright owner to the permission gained by the transferee. Further, the doctrine of implied licence is sensitive to the justifications that drive the implication of the licence, addressing the question as to why exhaustion must occur. Therefore, a framework called the Implied Licence Framework for Exhaustion is proposed here, which not only offers a better explanation for exhaustion and nonexhaustion, but also dispels the misconceptions.
\end{abstract}

A version of this paper was presented at the WIPO Advanced Intellectual Property Seminar held in Geneva in May, 2017. The author is grateful to the questions and comments raised at the seminar, and in particular to the comments of Dr Guy Pessach and Professor Martin J. Adelman. The author is also thankful to Professor Ansgar Ohly for reviewing an earlier version of the paper and providing his comments, to Professor Graeme Dinwoodie for his generous time and input, and to the anonymous reviewers for further improving this article.

P. Mysoor $(\bowtie)$

Dr; DPhil in Law; Graduate Teaching Assistant in Intellectual Property Law, Faculty of Law,

University of Oxford, Oxford, UK

e-mail: poorna.mysoor@law.ox.ac.uk 
Keywords Exhaustion · First sale $\cdot$ Digital exhaustion $\cdot$ Implied licence

\section{Introduction}

Exhaustion connotes the loss of a specific intellectual property right under certain defined circumstances. Having originated in the case law of the CJEU and the courts of certain Member States, exhaustion is now codified in the directives and implemented by the national laws. However, a peculiarity of exhaustion in relation to copyright is the express provision of non-exhaustion of certain rights. Currently, there are three distinct provisions in EU directives that address non-exhaustion of certain exclusive rights protected by copyright.

- Article 1(2) of the Rental and Lending Directive (2006/115) states that the rental and lending rights are not exhausted by any sale or other act of distribution of originals and copies of copyright works.

- Recital 43 of the Database Directive (1996/09) states that the right of reutilisation of a database is not exhausted by the online transmission of the database.

- Article 3(3) of the Information Society Directive (2001/29) (Infosoc Directive) states that the rights of communication and making available to the public are not exhausted by any act of communication or making available to the public of the copyright works.

However, there are many other rights that also do not exhaust, such as the right of reproduction, which have no express provision as to their non-exhaustion. Does this mean that rental and lending rights, the right of re-utilisation and the right of communication to the public are somehow different from rights such as the right of reproduction? If exhaustion applies only to rights for which express provision to that effect has been made, then it should follow that all those rights for which no such provision is made do not exhaust. Is there a reason behind expressly providing for non-exhaustion of some rights and not others? Do these provisions convey something more about the concept of exhaustion?

The exercise of the rights referred to above, namely rental and lending rights, online re-utilisation and the right of communication and making available to the public are all regarded as "provision of services" under the respective directives. ${ }^{1}$ Commentators have interpreted the CJEU case law to mean that the distribution of goods exhausts, while the provision of services does not. ${ }^{2}$ Although this may represent the trajectory of the case law of the CJEU in crystallising the concept of exhaustion, this article argues that the distinction of goods and services to determine when exhaustion occurs, and when it does not, conflates the complexities involved. Given that the rights that are not regarded as provision of services, such as the right of reproduction, also do not exhaust, it must be clear that the classification of goods

\footnotetext{
${ }^{1}$ InfoSoc Directive, Recital 29, and Database Directive, Recital 33.

2 Walter and von Lewinski (2010), para. 9.5.23.
} 
and services is no benchmark for exhaustion and non-exhaustion. This classification only leads to certain unfortunate misconceptions that for exhaustion to occur the copy of the work must be in a tangible medium and that for all provision of services authorisation is required.

If the classification of goods and services is unhelpful, what should it be replaced with to gain clarity and dispel misconceptions? This article argues that the root of the problem lies in the conceptualisation of exhaustion as a statutory phenomenon that leads to a loss of any intellectual property right for whatever reason; nonexhaustion being a derivation of this unrefined conceptualisation. This article proposes that one may achieve greater clarity on when exhaustion does or does not occur by reframing exhaustion within the common law doctrine of implied licence. It proposes to do this by focusing on the policy reasons that underlie exhaustion and conceptualising exhaustion as a policy-based licence implied by statute. Although copyright exhaustion has uniquely European origins, reframing it within the common law doctrine of implied licence may enhance its robustness as an enduring principle.

One may question the relevance of common law to EU law, especially in the light of Brexit. Firstly, EU law is a confluence of many legal traditions. Even with Brexit looming, it is premature to regard common law as irrelevant. Even if Britain makes a clean departure from both the EU and the EEA, Member States such as Ireland, Cyprus and Malta will continue to represent common law tradition. Secondly, the broad notion of implied licence is not as alien a concept to EU law as one might perceive; Soulier being the most recent example where a consent-driven implied licence was relied on. ${ }^{3}$ Thirdly, this article does not suggest amending the principles of exhaustion, but only reframing them. It suggests unpacking exhaustion and placing it in a context that better reflects its objectives, which can prevent conflation and bring nuance and clarity to the discussion. In this sense, what is derived from common law is only a method to underscore the teleological underpinnings of exhaustion.

This article begins by setting the context in which the exhaustion principle arose by pointing to the policy considerations that underpin it in Sect. 2. It demonstrates how the EU directives mask these policy objectives. It goes on to provide a snapshot of the doctrine of implied licence and reframes the concept of exhaustion as a licence implied based on these policy considerations by proposing the "Implied Licence Framework for Exhaustion". The article moves on to Sect. 3 to examine the circumstances in which the CJEU distinguished between goods and services for the purpose of exhaustion, which became the basis for conceptualising non-exhaustion, pointing out how, in formulating the directives, the EU legislature adopted certain generalisations that were unjustified. It goes on to re-analyse the case law and each of the provisions of non-exhaustion identified above in the light of the proposed framework, to demonstrate how this can bring clarity. Finally, in Sect. 4 the article points out two widely held misconceptions that result from the generalised distinction of goods and services: firstly, that exhaustion only applies to tangible

\footnotetext{
${ }^{3}$ Case C-301/15 Soulier v. Premier Ministre ECLI:EU:C:2016:878 at [36]. See Sect. 4.2 below for further discussion.
} 
property; and secondly, that to exercise any of the rights that amount to a service, authorisation from the copyright owner is required each time. The article concludes by underscoring the usefulness of the doctrine of implied licence to bring nuance and clarity to the understanding of exhaustion and non-exhaustion.

\section{Concept of Exhaustion}

Exhaustion, as the name suggests, captures only what happens to the copyright owner. Exhaustion is provided for in many directives: Art. 4(2) of the Infosoc Directive, which applies to all works of copyright and related rights, provides for the exhaustion of the distribution right within the EU/EEA. Exhaustion is also enshrined in the following other directives: Arts. 5(c) and 7(2)(b) of the Database Directive, Art. 4(2) of the Directive on Computer Programs (Directive 2009/24) (Software Directive), and Art. 9(2) of the Rental Directive. These provisions reveal that the focus is on the effect of the first sale or other transfer of ownership of the original or the copy of the work on the copyright owner, namely the consumption of the distribution right. Although such consumption is distinctly for the benefit of the transferee of the original or the copy of the work, these provisions do not reveal the effect of exhaustion on these transferees (referred to as the "copy owner" in this article). ${ }^{4}$ The opacity of these provisions conceals the reasons why exhaustion must occur and the policy justifications that drive such consumption. Especially if one wants to make sense of non-exhaustion, the justification for exhaustion must be clarified first. Understanding the mechanics of exhaustion and non-exhaustion can dispel the misconceptions that are a result of conflation of the complexities of exhaustion.

The doctrine of implied licence can help address these concerns. Framing exhaustion as an implied licence changes the focus from the right lost by the copyright owner to the permission gained by the copy owner. Further, the doctrine of implied licence is sensitive to the justifications that drive the implication of the licence, addressing the question as to why exhaustion must occur. It must be clarified, however, that what is being suggested is not that a court should imply a licence each time the circumstances arise. This article does not suggest an abandonment of exhaustion as a statutory principle and placing the power entirely in the hands of the judges. Exhaustion applies automatically to transactions when certain conditions are met and is not dependent on a court's decision before exhaustion can occur. Instead, what it recommends is to regard the statutory principle of exhaustion itself as a licence implied by a statute into a transaction because certain circumstances, i.e. certain policy reasons, are satisfied. In this sense, implied licence is used to reframe the context within which the statutory exhaustion takes place.

To achieve this, a framework called the "Implied Licence Framework for Exhaustion" is proposed here, which is elaborated in two stages - firstly, the

\footnotetext{
${ }^{4}$ In this definition, "copy" includes the original, as it makes no difference to this discussion whether the transferee acquires a copy or the original of the work.
} 
identification of the policy justifications underlying exhaustion; and secondly, how these justifications fit within the mechanism of implying a licence. Each aspect is dealt with below.

\subsection{Policy Justifications Underlying Exhaustion}

One of the objectives of the protection of copyright (or indeed any intellectual property) is to enable the person who creates the work to receive a just recompense for the time, effort and money expended in creating the work. The copyright owner may demand a recompense for the exercise of any of the exclusive rights protected by copyright by any other person. Where a copy of the work so created is incorporated into a product, such as a literary work in a book or a musical work on a $\mathrm{CD}$, the product may become the subject of trade. To extract her recompense, the copyright owner may consent to sell or transfer the ownership of the product. When a person acquires the ownership of the product incorporating the copy (namely, the copy owner) and wants to resell it, such resale amounts to the exercise of the right of distribution, requiring the copyright owner's permission. Each time the copy owner resells the product if he or she requires the copyright owner's permission it interferes with:

(i) the autonomy of the copy owner to alienate the product; and.

(ii) the trade in such products, whether at local, national or international levels.

Therefore, the compensation that the copyright owner can extract on the first sale or other transfer of ownership of such product is regarded as a just recompense so long as the sale or other transfer of ownership takes place with her consent. ${ }^{5}$ In principle, the product can be freely resold, and the copyright owner cannot assert her exclusive right of distribution to prevent such resale. ${ }^{6}$ In other words, the copyright owner has "exhausted" her right of distribution by such authorised first sale.

It is only the first transfer of ownership of the copy that must take place with the copyright owner's consent. The subsequent transfers ensue regardless of the copyright owner's consent, and achieve the objective of dealing with the interferences identified above, namely, with the autonomy of the copy owner to alienate the product; and with trade. In other words, as a matter of policy the law aims to preserve the autonomy of the copy owner and to facilitate trade. The word "policy" is used loosely here to denote a justification that is not borne out by and is external to the consent of the copyright owner. These external justifications, as will be seen below, can include jurisprudential reasons underlying the autonomy of the owner of personal property; and economic reasons underlying the facilitation of trade.

Exhaustion has a technical meaning, from both an historical and doctrinal perspective, in that it only refers to the loss of a specific right protected by copyright driven by the policy reasons explained below. Exhaustion does not refer to a general

\footnotetext{
5 Ricketson and Ginsburg (2006), para. 11.40.

6 Walter and von Lewinski (2010), paras. 5.4.33, 5.4.36.

7 Davies et al. (2016), paras. 24-18.
} 
loss of a right for any reason whatsoever. These policy justifications are closely related and are cumulative. The following paragraphs explain these justifications further.

\subsubsection{Preserving the Autonomy of the Owner of Personal Property}

The first act on the part of the copyright owner must be to consent to sell or transfer the ownership of a copy of the work. Once such a transaction takes place, Ricketson and Ginsburg explain that: ${ }^{8}$

the right of distribution is an incorporeal right that has a separate existence from the property rights in the product in which the work is embodied or reproduced. To extend the right of distribution so as to encompass the ways in which the product is distributed and subsequently dealt with brings these incorporeal rights into direct conflict with the rights of property that the owner of a copy enjoys once he has purchased it.

In Ricketson and Ginsburg's view, extending the right of distribution to this extent goes beyond what is reasonably necessary to ensure that the copyright owner enjoys the "fruits of the exploitation" of his or her intellectual creation. They assert that the rights of reproduction, adaptation and public communication all offer the required protection to the copyright owners. ${ }^{9}$

Many property theorists regard alienability as one of the defining features of personal property. ${ }^{10}$ It follows then that when a person acquires the ownership of personal property, he or she acquires the right to alienate it. Where a copy of the copyright work inheres in such personal property, the right to authorise distribution of the copyright work in such personal property could come into conflict with the exercise of the right of alienation of the owner of personal property, i.e. the copy owner. The copy owner will be required to seek the authorisation of the copyright owner whenever she wishes to alienate her property, thereby curtailing her right of alienation. Therefore, when a copyright owner sells or otherwise transfers the ownership of her work incorporated in a certain personal property, a curtailment of the distribution right becomes necessary. As a matter of policy, the right of alienation of the copy owner prevails over the distribution right of the copyright owner. This policy is referred to in this article as "property justification".

It may be further emphasised here that the first act by the copyright owner or with his or her consent does not have to be a sale of the copy, but can be any other form of transfer of ownership, such as barter or endowment. In this sense, sale is only one of the most common forms of transfer of ownership. ${ }^{11}$ Where a copyright owner gifts her work, she is taken to have waived her right to recompense. Such waiver by the copyright owner should not affect further alienation of the copy by the copy owner. Likewise, the copy owner can choose to sell the copy or transfer its

\footnotetext{
$\overline{8}$ Ricketson and Ginsburg (2006), para. 11.43.

9 Ricketson and Ginsburg (2006), para. 11.43.

${ }^{10}$ Bridge (2015), p. 2.
} 
ownership in any other manner. The focus, therefore, is on the alienation of the copy.

Jurists have tried to enumerate the rights of ownership of property in the form of a non-exhaustive list. ${ }^{12}$ Although a generic right to use the property is also regarded as an incident of ownership, certain kinds of use can be legitimately restrained to achieve other goals. For example, a person who purchases a book of poetry (the copy owner) can use the book in whatever manner he or she pleases. But in using the book if the copy owner makes copies of the content of the book, it may interfere with the right of reproduction of the author of the poetry, unless making such copies is captured within the limitations and exceptions recognised by copyright law, such as fair dealing for criticism and review. ${ }^{13}$ Making copies of the book is not regarded as part of normal enjoyment of the book. Therefore, the right of reproduction of the author prevails over the right of the copy owner to produce copies of the book. Similarly, in using the book of poetry, if the copy owner wishes to recite poetry in public it may interfere with the right of public performance of the copyright owner in the poetry. Since public recitation is not part of normal enjoyment of ownership of a book, as a matter of policy, the right of public performance of the copyright owner is given precedence. On the other hand, the most normal enjoyment of the book, which is to be able to read it, interferes with no right of the copyright owner. Although the idea of ownership of personal property is complex, the law has found a way to achieve a balance between the rights of the owners of personal property and intellectual property. ${ }^{14}$

Alienability is understandable more intuitively in case of tangible property than in case of intangible property. An illustration of a copyright work existing in an intangible medium is downloadable software. Certain case law under the UK Sale of Goods Act 1979 has held that unless the software in issue is recorded in a tangible medium, such as a CD or computer hardware, the software in itself is outside the purview of the 1979 Act. ${ }^{15}$ The definition of goods in the 1979 Act includes "all personal chattels" and expressly excludes things in action. Although not all intangibles are things in action, ${ }^{16}$ a significant objective of the 1979 Act is to regulate the sale of tangibles. Even if there are difficulties in applying the provisions of the 1979 Act to the sale of intangibles, the possibility of alienation of intangibles cannot be negated. Therefore, it is incorrect to conclude based on the case law under the 1979 Act that intangibles cannot be alienated. ${ }^{17}$

This view is explicable also from the perspective of property theory developed in the common law jurisdictions. The common law perspective is adopted here for its progressive and dynamic notion of property, in preference to the perspectives of other Member States. The term "property" covers a broad spectrum, a significant

\footnotetext{
${ }^{11}$ Walter and von Lewinski (2010), para. 11.4.49. See also Bently and Sherman (2014), p. 151.

12 Honoré (1961), pp. 107, 112-24.

13 See Copyright, Designs and Patents Act, Part I, Chapter III, Sect. 30(1).

14 See generally, Perzanowski and Schultz (2016), pp. 16-28.

15 St Albans City and District Council v. International Computers Ltd [1996] 4 All ER 481.

16 For example, Patents Act, 1977, Sect. 30(1) specifically says that a patent or patent application is personal property without being a thing in action.
} 
part of which is land. Once land is taken out, all else that remains is personal property. Within personal property, one can classify tangible and intangible property, and intangible property is further divided into intellectual property and all other intangibles not included in other categories. ${ }^{18}$ The property theory is reinforced by the legislative acceptance in the UK that intellectual property is property. ${ }^{19}$ This is why the expression "copyright owner" is used in this article in preference to the term "rightholder" in the EU directives. Although EU law does not have a harmonised notion of property, the common law notion of property is not too distant from the EU notion of property. In certain contexts, such as under Art. 1 of the First Protocol of the European Convention on Human Rights, an autonomous concept of "possessions" has been developed which extends similar protection to tangible and intellectual property. ${ }^{20}$ Further, Art. 17(2) of the EU Charter of Fundamental Rights conceptualises property to include intangible property, such as intellectual property.

In exhaustion, the rights protected for one form of personal property, namely intellectual property, clash with the rights protected for another form of personal property. The latter form of personal property can be either in tangible or intangible form, since the modern conception in common law of personal property is no longer restricted to tangible goods. ${ }^{21}$

If a copy of the work inheres in an intangible medium, the resulting product may be indistinguishable from the copy of the work itself. Despite this, it may be possible to show under certain circumstances that the copy of the work can be parted with permanently, similar to a copy that inheres in a tangible medium. Accordingly, in case of an intangible medium, it makes sense to first locate the existence of a copy of the work which is not a temporary copy and is such that it can be owned by the person to whom it is transferred, i.e. the copy owner. Thus, when the copyright owner transfers or consents to the transfer of ownership in the copy, the copy owner is free to sell the copy further to third parties. Such onward distribution by the copy owner does not require the copyright owner's consent, in recognition of the copy owner's autonomy as a property owner in her own right.

When the copy of the work is incorporated in an intangible medium, and the copy owner wishes to transfer his or her ownership in the copy, the copy owner may not be able to transfer the same copy that he or she receives from the copyright owner. There may be an additional copy created, thereby also involving the right of reproduction in addition to the right of distribution. Opponents of exhaustion in an intangible medium regard the involvement of the right of reproduction to be unacceptable. ${ }^{22}$ However, in achieving the objective of granting the copy owner the right to alienate her copy, if a new copy is created, to this limited extent, it appears

\footnotetext{
17 There is support for the view that the distinction between software in a tangible medium and downloadable software is untenable. See Bridge (2014), para. 2.23.

18 See generally, Bridge et al. (2013), para. 2.23.

19 Patent Act, 1977, Sect. 30(1), Copyright, Designs and Patents Act, 1988, Sect. 1(1) and Trade Marks Act, 1994, Sect. 2(1).

${ }^{20}$ Anheuser-Busche Inc v. Portugal (2007) 45 EHRR 36.

21 For example, Bridge (2015), pp. 10, 16.
} 
reasonable for the right of reproduction to be engaged. This also presupposes that despite the creation of a new copy for alienation, the copy that the copy owner originally acquired is destroyed or cannot be used by the copy owner upon alienation of the new copy.

With alienability at its heart, the property justification thus captures the policy of preserving the autonomy of the owner of personal property, whether such personal property is in tangible or intangible form.

\subsubsection{Facilitation of Trade}

Ricketson and Ginsburg opine that the exclusive rights of a copyright owner must be viewed in their wider economic context. A copyright owner may use her distribution right to divide up markets territorially and to secure exclusive chains of distribution that enable prices of copies to be artificially maintained while keeping other sellers of copies out of those markets. For this reason, they conclude that many national copyright laws operate in the wider context of trade practices and competition controls. These considerations also help to explain the limited protection given to the right of distribution under the Berne Convention. ${ }^{23}$

It takes the above argument on personal property to a commercial level. A person may acquire the ownership of commercial quantities of copies of a work for the purpose of selling them to third parties. The efforts of such person may create a market for the copies of the work. If the authorisation of the copyright owner was indeed necessary each time a copy is sold in the downstream market, then the copyright owner might authorise only subject to the price of such copies being fixed at a particular point. Such prices can create artificial demand, obstructing free trade by the application of market forces.

An illustration of this are the provisions governing the free movement of goods under the Treaty on the Functioning of the European Union (TFEU). ${ }^{24}$ Articles 34 and 35 TFEU prohibit any quantitative measures on imports and exports between Member States of the EU. Article 36 goes on to permit restrictions justified on the grounds of "protection of industrial and commercial property", so long as such restrictions do not "constitute a means of arbitrary discrimination or a disguised restriction on trade between Member States". In the CJEU's view, although copyright qualifies as commercial property under Art. 36, the exercise of the right of distribution to prevent importation of goods and to enforce price restrictions on the goods is an illicit restraint on the free movement of goods. Therefore, an uninhibited exercise of the right of distribution cannot benefit from Art. 36, although the right of distribution does protect commercial property. ${ }^{25}$ The CJEU made a distinction between the existence and the exercise of copyright; while the former does not affect the free movement of goods, the latter does. ${ }^{26}$ In a line of case law that followed, the CJEU crystallised the rule of exhaustion within the EU and the European Economic Area. ${ }^{27}$ As a matter of policy, the freedom of trade takes

\footnotetext{
22 Walter and von Lewinski (2010), para. 9.5.23.

23 Ricketson and Ginsburg (2006), para. 11.44.

24 OJ C 326 (26 October 2012).
} 
precedence over the full protection of the distribution right of the copyright owner. In this article, this policy justification is referred to as "trade justification".

It may be emphasised that the concern here is only trade in its simplest form which is the buying and selling of copies of the work. A person who acquires the ownership of a copy may engage in a trade that presses into service a right other than the distribution right. For example, a person purchasing music on a CD might wish to perform the $\mathrm{CD}$ publicly in his or her night club. Even though this is a legitimate trade, in facilitation of this trade the right to public performance of the copyright owner of the music incorporated in the CD is not exhausted. The only right that interferes with trade in this sense is the right of distribution, since no other right interferes with a trader's ability to sell the copies of the work she owns. In this sense, trade justification is also deeply rooted in the idea of alienation, similar to property justification.

Simply because exhaustion was crystallised in the context of trade in tangible goods does not mean that as a concept it cannot extend to intangibles. If a copy can be alienated, whether it is in a tangible or intangible medium, a trade in the simple sense of buying and selling such copy is perfectly conceivable. In this vein, the agreed statement in relation to Art. 6 of the WIPO Copyright Treaty (WCT) that the originals and copies mentioned in that provision only refer to those incorporated in tangible objects is unhelpful. Ironically, the purpose of the WCT was to introduce new international copyright rules in the light of the developments in communication and information technologies. When trading in intangible objects is made possible by these very technologies, it appears pointless to be constrained by the agreed statement in conceptualising exhaustion as applying to only tangible objects.

With alienation at its core again, the trade justification captures the policy of facilitating trade, regardless of whether the trade is in tangible or intangible objects.

\subsection{Exhaustion as a Policy-Based Implied Licence}

How does the identification of the policy justification underlying exhaustion assist in gaining a more complete understanding of exhaustion? Reframing exhaustion as a licence implied based on these policy justifications can achieve this objective. It should not be too strange to suggest a common law solution to an EU law problem since certain non-common law scholars also support the view that exhaustion is rooted in implied licence. ${ }^{28}$ When exhaustion leads to the consumption of the distribution right of the copyright owner, there is a corresponding gain on the part of the copy owner, reflected in the copy owner being permitted to exercise the right of distribution regardless of the copyright owner's consent. In other words, the ownership of copyright remains with the copyright owner, but the copy owner gets to exercise one of the exclusive rights. This means that exhaustion has the effect of

\footnotetext{
25 C-78/70 Deutsche Grammophon v. Metro [1971] ECR 487.

26 C-40/70 Sirena v. Novimpex [1979] ECR 3169.

27 C-55/80 and C-57/80 Musik-Vertrieb Membrand/K-tel v. GEMA [1981] ECR 147; culminating in C-58/80 Dansk Supermarked v. Imerco [1981] ECR 181. See also Walter and von Lewinski (2010), paras. 11.4.20, 11.4.29-11.4.30.
} 
granting the copy owner a licence. Since the licence is not expressly granted but implied from a statute, and the driving force of such licence lies in the two policy justifications explained above, exhaustion can be conceptualised as a policy-based implied licence. The mechanics of implication and how the policy justifications drive such implication need to be explored.

\subsubsection{The Doctrine of Implied Licence in Copyright Law}

For one to understand the mechanics of implication, one needs a snapshot of the common law doctrine of implied licence, and to locate exhaustion within this larger doctrine. The doctrine of implied licence captures the space between express licences by the copyright owner on the one hand and the statutory limitations and exceptions on the other. ${ }^{29}$ Exhaustion is located within this spectrum.

Although implied licence had been applied in many decisions in the UK, there had been no manner of orderly study of these decisions to ascertain what drives the implication in these cases. In classifying implied licences according to the justifications that drive the implication, one may draw inspiration from the common law principles of implication of a term into a contract. At common law, there is well-established jurisprudence supporting implication of a term into a contract, classified based on the justifications that drive the implication:

(i) implying a term that captures the unexpressed joint intention of the parties to the contract. A term so implied is normally called "implied in fact". ${ }^{30}$ An example is where a wharf owner charges a fee to provide mooring service, the unexpressed joint intention of the parties is that the wharf owner takes on a duty of care that the seabed is safe for mooring; ${ }^{31}$ and

(ii) implying a term that captures the normal incidences necessarily found in a particular type of contract. A term so implied is normally called implied by law, because the driving force of implication is not the intention of the parties, but a court trying to achieve policy objectives such as fairness or efficiency. ${ }^{32}$ An example is where a state sector landlord leases premises in multi-storeyed buildings, a term is implied into all leases of this type that the landlord must maintain common areas, even if this was not apparent from the intention of the parties. $^{33}$ The underlying policy being achieved is a more efficient allocation of risk between the parties (although the court does not specifically state so). ${ }^{34}$ Over time, many such terms implied by courts become embodied within a statute, and are implied from such statutes into all contracts of a particular kind. ${ }^{35}$

\footnotetext{
Oxford 2017).

30 McMeel (2011), para. [10.04].

31 The Moorcock (1889) 14 PD 64 (CA).

32 McMeel (2011), paras. 10.01-10.15.
}

${ }^{28}$ One may find support in Hilty (2016), pp. 64, 67.

29 Until recently there was no comprehensive work focusing on implied licences in copyright law. This gap has recently been filled by P Mysoor, Implied licences in copyright law (DPhil thesis, University of 
(iii) Some scholars speak of a third type of implication - implied by custom or usage. However, this is not very relevant to the discussion here. ${ }^{36}$

While this line of authority applies to implying any term generally into a contract, it can also guide the implication of a specific kind of term into a contract, namely a copyright licence. Just as a term can be implied into a contract because it represents the unexpressed joint intention of the parties, a copyright licence can be implied into a contract too if it can be shown that the copyright owner consented by her conduct and the circumstances. Since consent of the copyright owner drives the implication of the licence, one can call it consent-based implied licence. Similarly, just as a term can be implied into a contract by courts or by statute to achieve policy objectives, a copyright licence can be implied into a contract to achieve policy objectives. Since the achievement of a policy objective drives the implication, one can call it a policybased implied licence. ${ }^{37}$

The classification of implied licences based on the justification that drives the implication is central to the doctrine of implied licence. The advantage of such classification is that the core characteristics of each type of implied licence can be separately examined and understood. Accordingly, when the copyright owner's consent drives an implied licence, the copyright owner is well within his or her powers to incorporate express words that override any implication of a licence. When a policy drives the implication of a licence, whether the copyright owner can incorporate express terms that override an implication of a licence will depend on the strength and gravity of the policy. If, for example, the policy is free movement of goods which is one of the fundamental tenets of EU law, the incorporation of an express term overriding or excluding it is unlikely to be given effect by a court. When the copyright owner's consent drives implied licence, it is possible for the copyright owner to withdraw or terminate her licence, since it is within the copyright owner's powers to take back his or her consent. ${ }^{38}$ However, when a policy drives implied licence, the copyright owner cannot withdraw or terminate the licence because it is not in his or her powers to do so. So long as the policy justification still holds good, the implied licence continues. This is particularly the case if the licence is embodied in a statute like it is in exhaustion and is implied from the statute. Therefore, if we are able to characterise exhaustion as a policybased implied licence, it helps in ensuring that the copyright owner does not have the ability to override implication of this licence, nor can he terminate or withdraw it.

\footnotetext{
33 Liverpool City Council v. Irwin [1977] AC 239, 253-54.

34 Peden (2000), pp. 459, 467-75.

35 See Sale of Goods Act, 1979, Sect. 14(2) on implying into contracts of sale of goods a term as to the satisfactory quality of the goods.

36 McMeel (2011), para. 12.11.

37 P Mysoor, supra note 29.

38 This depends on whether the implied licence is a bare or a contractual one. If it is a bare licence, nothing prevents the copyright owner from withdrawing consent, thereby ending the licence. If it is a contractual licence, then the rules of termination of a contract will apply before a copyright owner can withdraw his or her consent.
} 
What if a transaction does not amount to a contract? Can a copyright licence still be implied into such transaction? Where a copyright owner parts with the original or the copy of her work gratuitously, the lack of consideration flowing from the counter-party prevents the resulting transaction from becoming a contract under common law. While the transfer of the original or the copy itself may be regarded as a gift, if a licence to use the copyright work is to be implied, such licence becomes a bare licence. In English common law, one can identify cases where courts have implied a consent-based bare licence ${ }^{39}$ as well as a policy-based bare licence (though in the latter the courts do not admit to doing so). ${ }^{40}$ In addition to courts implying a bare licence, in principle, there is no reason why by virtue of a statute a bare licence cannot be implied into a transaction that does not amount to a contract, if the circumstances for its implication exist.

The doctrine of implied licence is not only sensitive to the justifications that drive implication, it is also agnostic as to whether the transaction between the copyright owner/licensor and the user/licensee is a contract. This is exactly the kind of framework that one needs to explain exhaustion because the focus of exhaustion is whether there is a transfer of ownership of the original or copies, regardless of whether such transfer amounts to a contract. Further, the tangibility or intangibility of the copies being transferred also does not matter to the application of the doctrine of implied licence so long as the policy justifications are served. This helps to maintain the focus of the enquiry on the teleological essentials of exhaustion. The paragraphs below demonstrate this.

\subsubsection{Implied Licence Framework for Exhaustion}

The concept of exhaustion in English common law first originated in patent law, although it was not named as such then. One may refer to the common law rule in Betts $v$ Willmott, ${ }^{41}$ where a product patented in England had been purchased lawfully in France and resold in England. The issue was whether the patentee can require such resale in England to take place only with the patentee's consent. Lord Hatherley held: ${ }^{42}$ "[W]here a person carries on the two manufactories himself, and himself disposes of the article abroad, ... he transfers with the goods necessarily the licence to use them wherever the purchaser pleases. When a man has purchased an article he expects to have the control of it".

Lord Hatherley therefore found that there was no unauthorised use. The significance of Betts lies in its use of the language of licence - permitting the purchaser of a patented product to sell the product without having to seek such permission from the patentee. Such licence does not arise because the patentee consents, but because the purchaser of the product expects to have control over the product.

\footnotetext{
39 Banks v. CBS Songs Ltd [1996] EMLR 440.

40 Beggars Banquet v. Carlton [1993] EMLR 349.

41 (1871) LR 6 Ch App 239.

42 Ibid., at 245 (emphasis supplied).
} 
How did the Betts principle rooted in patent law travel to copyright law? The truth is that it did not. The UK copyright law did not have the need to take assistance from implied licence in relation to resale of products incorporating copyright works. This is because, until 1988, the UK copyright legislation only protected the right of first publication, and not a general right of distribution. ${ }^{43}$ Thus, once the copyright owner had exercised her right of first publication, the right ended there and did not extend to the resale market. The copyright owner could not assert her right of first publication to prevent further distribution. ${ }^{44}$ However, with the enactment of the Copyright, Designs and Patents Act, 1988 (CDPA), a general right of distribution was introduced, together with the provision for international exhaustion originally, which was amended to EU-wide exhaustion at a later date. The statutory embodiment of exhaustion both under the CDPA and the EU directives has taken away the need for the courts to imply a licence into a transaction, as the statutory principle of exhaustion is read into such transactions in any event. However, instead of calling it the statutory phenomenon of exhaustion, if that phenomenon is characterised as a licence implied by a statute to achieve certain policy objectives, then it may shed light on the mechanics of exhaustion to bring greater clarity.

The principle to be derived from Betts is that the purchaser of the patented product receives a licence to resell the product. This licence arises not because the patentee consents to such licence, but because the purchaser expects to have control over the product she purchases. When this principle is transposed to the copyright context, then one may discern that a licence is implied into the contract of sale permitting the copy owner to exercise the right of further distribution of the copy. The copy owner enjoys this licence regardless of the copyright owner's consent, since consent of the copyright owner is irrelevant after the first sale of the copy. Instead of regarding consent as irrelevant, it brings greater clarity if one puts forward the policy reasons that justify the irrelevance of consent. Applying Betts one might regard the justification as coming from the copy owner's expectation to have full control over the product she purchases. This, at its core, refers to the alienability on the part of the copy owner. The alienability, as discussed above, is captured by the property justification and trade justification. Therefore, exhaustion is a policy-based implied contractual licence, with these two justifications as the bases.

One may ask what happens when the copy owner further transfers the copy of the copyright work to someone else, and such transferee further transfers the copy and so on? Does the implied licence move with such transfer for the benefit of each third-party transferee? Again, since exhaustion can be characterised as a policybased implied licence, so long as the subsequent transfers maintain conditions that fulfil the policy objectives of property and trade justifications, then the implied licence based on these policies continues to attach to such subsequent transactions. For exhaustion, this is further facilitated by the source of implication being a statute,

\footnotetext{
43 Some common law countries, for example, Australia and Singapore, even now only provide for the right of first publication, giving the copyright owner the sole prerogative of determining when the first issue of copies of her work to the public will take place. There is no general provision relating to the distribution of copies, except certain other limited rights, such as the right of importation.

44 Phillips and Bently (1999), p. 133.
} 
such that the statutory licence is implied automatically if the policy objectives are fulfilled. As we have seen from the discussions above, the fundamental requirement that triggers these justifications is alienation of the copy. So long as there is an alienation of the copy at any point down the chain of distribution, a licence is implied by the statute to facilitate further distribution based on the property and trade justifications. Instead of characterising the original licence as being implied for the benefit of all third-party subsequent acquirers of the copy, it would be more coherent to regard it as a new licence implied by statute having come into existence in favour of the respective transferees due to the continued existence of the policy reasons that justified the original licence.

As clarified above, sale is only one form of transfer of ownership, and there may be others such as a gift of the copy, which may not amount to a contract under English law. Therefore, if there is no contract, it should be possible to imply a bare licence into the transaction. The policy justifications remain the same whether there is a contract for sale or other transfer of ownership not amounting to a contract, so long as there is alienation of the copy. Thus, in cases where the copyright owner consents to the transfer of ownership of a copy of her work in situations where no contract is formed, it is possible to imply a bare licence based on the property and trade justifications leading to exhaustion.

Normally, the licence permits the exercise of the distribution right by the copy owner without the consent of the copyright owner if the copy of the work inheres in a tangible medium. If the copy of the work inheres in an intangible medium, as described above, in addition to the distribution right, the copy owner may also need to exercise the reproduction right. Therefore, not only the distribution right but also the reproduction right may need to be impliedly licensed to the limited extent of enabling alienation by the copy owner and the achievement of the policy justifications of exhaustion. Since alienation means that the copy owner should no longer have the use of her copy of the work, the implied licence permitting the exercise of the reproduction right should be conditional on the copy owner's copy being destroyed or rendered unusable.

Thus, described in terms of implied licence, exhaustion represents a policy-based statutorily implied contractual or bare licence (depending on the circumstances), permitting the exercise of the distribution right (and the reproduction right to a limited extent, depending on the circumstances) driven by the two policy justifications - property justification and trade justification. This explanation of exhaustion captures both the cause and effect produced by exhaustion on both the copyright owner and the copy owner, thereby accounting for a comprehensive understanding of exhaustion. This is the Implied Licence Framework for Exhaustion. It will be seen below how the level of clarity brought by this framework is important to explain the idea of non-exhaustion, and to dispel some of the misconceptions that arise from the current understanding of exhaustion. 


\section{Understanding Non-exhaustion}

With the concept of exhaustion thus explained, what does it mean for a right not to exhaust? It means either that one or both the property and trade justifications driving exhaustion do not exist, or that the consumption of the corresponding right of the copyright owner is attributable to reasons other than property and trade justifications. Accordingly, if the right of alienation of the copy owner is not affected by the exercise of a right by the copyright owner, then no such right of the copyright owner is exhausted. Or if the exercise of a right by the copyright owner does not interfere with free trade in goods, then no right of the copyright owner is exhausted. In the language of implied licence, if the copy owner only has the benefit of a licence implied based on some other policy justification, or on one of the other bases such as consent of the copyright owner, no exhaustion can occur.

So long as her right to alienate the copy is not interfered with, which only the right of distribution does (and to a limited extent, the reproduction right in the digital medium), no other right of the copyright owner will be regarded as an illegitimate interference with the rights of the copy owner. Thus, no right other than the right of distribution exhausts. In this sense, no provision for non-exhaustion of any right should be necessary.

Although the above concept appears simple enough, one cannot deny that this analysis of non-exhaustion is with the benefit of hindsight, and assumes that the exhaustion principle was crystallised first, based on which non-exhaustion was conceptualised. Historically this is not how non-exhaustion arose. It arose alongside exhaustion, during a time when the Community rules on the free movement of goods and free provision of services were being crystallised. The discussion below recounts this development.

\subsection{The Coditel Decisions}

Not all exclusive rights protected by copyright address copies of the work. Some rights address the performance of the work. Exhaustion is a concept distinctly attached to copies of the work, which is why concepts such as transfer of ownership of a copy of the work make sense. In case of rights like public performance, broadcasting and communication to the public, however, it does not make sense to speak in terms of a copy of the work parted with by the copyright owner. It is either because the user does not receive a copy of the work (for example, where the user watches a movie at the cinema) or because she does not acquire the ownership of a copy of the work (for example, where her television antenna receives temporary copies of the work for display on her television screen). The corresponding rights of the copyright owner operate differently. A series of cases were brought before the CJEU in this regard at a time when the CJEU had been engaged in crystallising exhaustion of the distribution right to facilitate the free movement of goods between Member States. Since no issue could be raised with copies of the work and with free movement of goods, as a matter of trade between Member States the arguments were couched in terms of freedom to provide services. The following cases demonstrate this. 
A group of Belgian companies called Coditel received the signals for a film lawfully broadcast in Germany and aired them to their customers in Belgium. The company which had the exclusive rights to show that film in Belgium, SA Ciné Vog Films, sued the Coditel companies for copyright infringement and damages. ${ }^{45}$ Coditel in turn argued that such a claim for infringement interferes with their freedom to supply services under Art. 49 EEC Treaty (now, Art. 56 TFEU). The CJEU held that:

(i) The exercise of the right to performance by the owner of copyright in a film should be regarded as a supply of services, rather than provision of goods; the exploitation of the film depends on repeated performance, rather than circulation of material copies; ${ }^{46}$ this means that distributing copies of literary and artistic works to the public is inseparable from the circulation of the material form of the works, as in the case of books or records, whereas a film belongs to the category of literary and artistic works made available to the public by performances which may be infinitely repeated, irrespective of the method of public diffusion, whether cinema or television; ${ }^{47}$ and

(ii) The freedom to supply services does not prevent an assignee of the performing right in a cinematograph film in one Member State (i.e. SA Ciné Vog) from relying on its right to prohibit the film being broadcast, even if the film is retransmitted after being picked up from a broadcast emanating from another Member State. ${ }^{48}$ The rules on freedom to supply services do permit the performance right in films to be divided into geographical areas. The mere fact that such geographical areas coincide with the boundaries of Member States does not violate the provisions on freedom to supply services. ${ }^{49}$

Thus, the decision in this case and the case law that followed ${ }^{50}$ became the basis for the principle that exhaustion applies to distribution of goods, and not to provision of services. The distinction of goods and services might be reasonable from the point of view of trade rules within the internal market. However, the distinction cannot be the sole basis for exhaustion and non-exhaustion because it oversimplifies these concepts. This can be demonstrated by analysing the Coditel cases under the Implied Licence Framework for Exhaustion.

\subsection{Coditel Analysed Under Implied Licence Framework of Exhaustion}

When the film was broadcast in Germany with the consent of the film producer, if such broadcast amounted to a sale or other transfer of ownership in a specific copy of the film, then the right to broadcast would have exhausted. The Coditel companies could not have been stopped from capturing the signal and further

\footnotetext{
45 Coditel I [1981] FSR p. 535 and Coditel II [1983] FSR p. 148.

46 Coditel I [1981] FSR p. 535.

47 Coditel II [1983] FSR p. 148, para. [11].

48 Coditel I [1981] FSR p. 535.

49 Coditel II [1983] FSR p. 148 para. [15].

50 Case C-395/87 Ministere Public/Jean-Louis Touriner [1989] ECR 2521.
} 
broadcasting the film. But broadcast of a film does not amount to a sale or other transfer of ownership because in the process of transmission, several copies of the film are made, and there is no single identifiable copy that could be regarded as the focus of exhaustion. Moreover, these copies are not made available to the recipient permanently. The copyright owner can exercise control over the copies she makes available by withdrawing them after being exhibited through broadcast. This means, by telecasting a film, a copyright owner can ensure that the copies that appear on the television screen appear temporarily while being exhibited and disappear after it. When no transfer of ownership of a copy has taken place, the recipient of the copy does not become the owner of the copy for her to exercise the right of alienation. Therefore, the property justification is not satisfied.

From the Coditel decisions, it does appear that the manner in which a copyright owner or her exclusive licensee can divide up the market for broadcasts and charge differential pricing interferes with the trade in services. However, the CJEU opined that this is a legitimate interference with trade because it is inherent in the nature of copyright that a film producer should be able to derive royalties from each showing of her film. Even the division of the market based on the geographical boundaries of Member States was found acceptable within the provisions protecting freedom to provide services because in the 1980s broadcasting was a national monopoly. This also appears to be an interference with trade. However, as explained above, the focus of trade justification is only trade in its simplest form, which is buying and selling. The manner of exploitation in the Coditel cases was by broadcast, which did not involve buying or selling of copies of the work. The division of the market and price differentiation for any mode of exploitation other than by simple distribution is permissible. Thus, the trade justification is also not satisfied.

In the language of implied licence, since neither the property justification nor the trade justification were found to exist in the Coditel case, these justifications could not form the basis for implying a licence in favour of the Coditel companies. Indeed, no licence could be implied in favour of the Coditel companies on any other basis either - such as consent of the copyright owner or its exclusive licensee (namely SA Ciné Vog). This is because neither the copyright owner nor SA Ciné Vog had consented to the film being received by the Coditel companies. Not being beneficiaries of any implied licence, the Coditel companies had to seek permission from SA Ciné Vog. In granting the permission, the CJEU in effect considered it fully legitimate for the copyright owner to divide the market and charge differential pricing.

It is clear from the foregoing discussion that the distinction between goods and services is irrelevant to the application of the two policy justifications, even if the distinction was essential in the historical context of formulating trade rules within the Community. This distinction is not helpful in providing a meaningful basis for exhaustion and non-exhaustion. Instead, it is the Implied Licence Framework for Exhaustion that leads to a clearer understanding of why exhaustion did not occur in the Coditel cases. Some commentators state that a ruling in a specific case like Coditel leading to a general principle of non-exhaustion of the communication right is unwarranted. ${ }^{51}$ Despite this, the Coditel cases were influential not only on 
subsequent case law, ${ }^{52}$ but also on the codification and harmonisation of EU copyright law on exhaustion.

\subsection{Non-exhaustion Provisions Analysed Under Implied Licence Framework for Exhaustion}

In crystallising, harmonising and codifying the law on exhaustion, the EU law in effect reflects the prevailing case law, and provides that the principle of exhaustion only applies to the distribution of goods, but not to the supply of services. ${ }^{53}$ Accordingly, Recital 29 of the Infosoc Directive provides that the question of exhaustion does not arise in case of services in general, and online services in particular. Renting copies of a work is offered as an example of services, and Art. 1(2) of the Rental Directive provides for the non-exhaustion of the rental right upon the first sale or other transfer of ownership of the work. Recital 33 of the Database Directive provides for the distribution of online databases as an example of online services, and Recital 43 provides for non-exhaustion of the right of re-utilisation upon the online distribution of the work. Article 3(3) of the Infosoc Directive provides for non-exhaustion of the right of communication to the public. Although the Infosoc Directive does not expressly state that the exercise of the right of communication or making available to the public is a provision of services, given the historical background of the Coditel cases, it could be regarded as such. Thus, the distinction of goods and services underlies all provisions on non-exhaustion.

At first sight it may simply appear that the provisions on non-exhaustion are an innocuous statement of the obvious. This was indeed reinforced during the drafting of certain provisions. In the case of Art. 3(3) of the Infosoc Directive, it was noted that no one would seriously question that the exclusive right of making available to the public must not be exhausted by such making available and that this provision is only a clarification. ${ }^{54}$ However, these provisions in the directives are an expression of a generalisation that the provision of services does not exhaust, which takes away from the nuance required to appreciate exhaustion and non-exhaustion. When analysed in the light of the Implied Licence Framework for Exhaustion, it becomes clear that the conception of these rights as a provision of services conflates a more complex analysis. The following paragraphs explain each of these provisions in the light of the framework.

\subsubsection{Article 1(2) of the Rental Directive}

If a copyright owner sells books in which her literary work is incorporated, for example, then her rental right in relation to that book is not exhausted. This means that the purchaser of the book (the copy owner) is not free to rent the book to third

\footnotetext{
51 van Eechoud (2009), p. 312.

52 Case C-395/87 Ministere Public/Jean-Louis Touriner [1989] ECR 2521.

53 Walter and von Lewinski (2010), para. 5.4.38.

54 Explanatory memorandum on Art. 3 (para. 2, note 4). See also Walter and von Lewinski (2010), para. 5.4.39.
} 
parties; the copy owner must obtain the copyright owner's authorisation to rent her copy of the book to third parties. Renting her copy of the book to third parties falls short of alienating the copy, since renting and lending are temporary making available of the copy or the original of the work. ${ }^{55}$ Also, the rental or lending market for the book is a distinct market and does not interfere with the market for reselling of the book. Since the right of the copy owner to alienate the copy is not affected, neither the property justification, nor the trade justification is satisfied in this scenario.

Applying the Implied Licence Framework of Exhaustion, the licence implied into the contract of sale or other transfer of ownership based on policy justifications, namely, property justification and trade justification, only permits the copy owner to further distribute the copy, meaning part with its ownership. The implied licence does not extend to the exercise of any other right, including the rental right. It is therefore obvious that the rental right is not exhausted by any sale or other act of distribution of originals or copies of copyright works.

Article 1(2) of the Rental Directive did not have to provide specifically for nonexhaustion. Some commentators explain that in some Member States the rental right was classified under the distribution right, and the fear was that just as the distribution right exhausted, the rental right too might exhaust. Therefore, it was regarded necessary to clarify that the rental right did not exhaust. However, with the Rental Directive placing a distinct obligation on the Member States to enact a separate rental and lending right, the fear of confusion with the distribution right appears unfounded. Further, Art. 9(2) of the Rental Directive itself confirms that the only right that exhausts upon the first sale or other transfer of ownership of the copy is the right of distribution.

That the provision for non-exhaustion of the rental right is superfluous cannot be doubted. The only reason why this was provided appears to be that rental and lending are characterised as provision of services. This is unhelpful as it conceals the more rigorous analysis provided above.

\subsubsection{Recital 43 of the Database Directive}

Recital 43 of the Database Directive provides for the non-exhaustion of the right of re-utilisation in a copy of the database upon its online transmission, although there are no substantive provisions on non-exhaustion in that Directive to reinforce it. The distribution of an online database is regarded as a service under Recital 33 of the Database Directive.

The initial act performed by the copyright owner is not the sale or other transfer of ownership, like in the case of Art. 1(2) of the Rental Directive, but online transmission. However, Recital 43 must be read with the substantive provision under Art. 7(2)(b) of the Database Directive, which states that the sale or other transfer of ownership of a copy of a database does exhaust the distribution right. It should follow that if the online transmission effects the sale or other transfer of ownership of copies of the database, then exhaustion still occurs. If online

\footnotetext{
$\overline{55}$ Rental Directive, Art. 2(1)(a) and (b).
} 
transmission does not generate copies whose ownership can be acquired by the recipient of such transmission, then there is no possibility of the recipient's right of alienation being unduly interfered with. Thus, without further information regarding the nature of the copies generated during transmission and their alienability, it is unclear whether the property justification or the trade justification is satisfied.

The initial act of online transmission also does not provide clarity as to the transaction taking place - whether a contract has arisen or not. However, as explained above, the Implied Licence Framework for Exhaustion accommodates both a contractual and non-contractual scenario, so long as there is a transfer of ownership. If the online transmission amounts to a contract of sale or other transfer of ownership, one may ascertain if a licence could be implied into such contract based on policy justifications to permit re-utilisation of the database. If the online transmission does not amount to a contract, but nevertheless a transfer of ownership, then a bare licence may be implied into such transaction based on the policy justifications, if these justifications are satisfied. Therefore, the key aspect that must be determined first is the nature of copies generated and their alienability, which in turn sheds light on whether the property and the trade justifications are satisfied.

Under these circumstances, non-exhaustion only indicates that a licence cannot be implied based on the policy justifications underlying exhaustion. It may still be possible to imply a licence based on other policy reasons or on other bases (such as consent). Therefore, simply providing under Recital 43 a generalised statement that an online transmission of a database does not lead to exhaustion of the right of reutilisation is misleading.

Recital 43 not only regards all distribution of online databases as a service, but also makes it the reason why exhaustion does not occur in relation to distribution of online databases. Simply because the database is in digital form does not in itself make the distribution of a copy of such database a service, making its exhaustion impossible. This only serves to conflate the analysis and takes it away from the nuanced analysis that is required to assess the kind of copies that are generated due to such distribution.

\subsubsection{Article 3(3) of the Infosoc Directive}

Under Art. 3(3) of the Infosoc Directive again, the first act on the part of the copyright owner presumably is not a sale or other transfer of ownership, but the exercise of the right of communication or making available to the public. However, the copies generated during such communication may or may not be of the type that enables the recipient to acquire ownership of the copy. If the communication to the public generates many temporary copies which only pass through the respective channels of communication (be it a wire or wireless transmission), then there is no possibility for the recipient of the communication to acquire ownership of the copy. The recipient in effect does not become a copy owner. On the other hand, if it can be shown that the recipient of the communication in fact received an identifiable copy of the work, whose ownership was transferred to the recipient (copy owner), then the further distribution by the copy owner should be free of control by the copyright owner. Thus, it is not because communication or making available are services that 
exhaustion does not occur; rather, it is because of the nature of the copies generated during communication or making available and their alienability. Depending on the nature of the copies generated and their alienability, one may ascertain if the property justification or trade justification is satisfied.

The initial act by the copyright owner is an act of communication or making available to the public, which may or may not take place within a contractual context. As explained above, if a contract can be identified, then one can ascertain whether a licence may be implied based on the policy justifications for exhaustion. If no contract can be identified, then one may ascertain whether a bare licence may be implied based on the policy justifications. Under these circumstances, the nonexhaustion of the communication right only means that no licence may be implied based on the property justification or trade justification, or both. However, it may still be possible to imply a licence based on other policy reasons or on other bases such as consent.

Thus, just as in relation to online distribution of databases discussed above, in case of communication and making available to the public, exhaustion or nonexhaustion does not depend on whether these are characterised as services. It depends on the nature of the copies generated during such communication or making available to the public, and their alienability.

\section{Misconceptions Arising from Goods and Services Distinction}

If the legislative intent behind the distinction of goods and services for exhaustion purposes was to bring clarity, then the distinction would still have been innocuous. After all, the free movement of goods and free provision of services are at the heart of trade within the EU. However, both Recital 29 of the Infosoc Directive and Recital 33 of the Database Directive provide that unlike cases where the work is incorporated in a material medium (such as a CD-ROM), every online service is an act for which the copyright owner's authorisation will be required. The logical corollaries of this provision lead to certain major misconceptions: firstly, that the lack of a material medium underlies the distinction between goods and services, and therefore exhaustion occurs when a copyright work is incorporated in a material medium, and does not occur if incorporated within a non-material medium; and secondly, that for every exercise of the service, permission from the copyright owner is required. The following paragraphs deal with each of these misconceptions.

\subsection{Digital Exhaustion Does Not Exist}

Commentators opine that the case law of the CJEU has distinguished between, on the one hand, the right of distribution in tangible form and the free movement of goods for which exhaustion applies and, on the other, uses occurring in non-tangible form and the free movement of services, to which exhaustion does not apply. ${ }^{56}$ Instead of ascertaining whether the provision of services can amount to the exercise of the right of distribution by analysing the nature of copies generated and their 
alienability, the law simply regards it as a service and denies exhaustion indiscriminately.

Remarkably, the absence of provisions, such as Recital 29 and Art. 3(3) of the Infosoc Directive, has enabled the CJEU to take a different view in relation to software under the Software Directive. The issue arose in the context of the online distribution of software in UsedSoft GmbH $v$ Oracle International Corp. ${ }^{57}$ In this case, Oracle offered group licences to its software and one such recipient of the licence was UsedSoft. UsedSoft in turn marketed used software licences including those of Oracle. Oracle sued UsedSoft for infringement claiming that its rights in the software had not exhausted. ${ }^{58}$ The CJEU did not discuss the nature of the copies that UsedSoft had acquired. But unlike the Coditel companies which had received temporary copies aired in a broadcast, UsedSoft had acquired permanent copies of the software. Since UsedSoft would have been able to own and alienate the software if it had been incorporated in a medium such as a $\mathrm{CD}$, the question was whether the mere absence of the material medium made the copy not ownable. The CJEU's approach was that if it could be established that UsedSoft purchased the copy from Oracle, then UsedSoft can resell it. Simply put, if a copy can be purchased, it can be sold. The CJEU therefore analysed the transaction between Oracle and UsedSoft to see if the copy was alienated.

The CJEU held that the commonly accepted definition of sale is "an agreement by which a person, in return for payment, transfers to another person his rights of ownership in an item of tangible or intangible property belonging to him". 59 Although the agreement itself was named a "licence" and one of the terms was that the licence was not transferable, the CJEU held that the act of downloading the software and concluding the agreement should be regarded as one transaction. On this basis, the Court held that a customer of Oracle who downloads a copy of the software and concludes the user licence agreement receives in return for the payment of a fee a right to use that copy for an unlimited period of time or "permanently". In the CJEU's view, this is akin to a transfer of ownership, and it makes no difference whether the software is incorporated in a material medium such as a CD-ROM or DVD, or downloaded from the internet. ${ }^{60}$ The CJEU confirmed that the term "sale" should be interpreted broadly to include all forms of product marketing by which the right to use is granted in a software for an unlimited period in return for a payment of a fee designed to enable the copyright owner to obtain a remuneration corresponding to its economic value. If one went only by labels such as licence, then exhaustion can simply be avoided by calling the transaction a licence. ${ }^{61}$

An argument had been raised as to the applicability to software of nonexhaustion of the communication right enshrined in Art. 3(3). One might view the CJEU's opinion that the Software Directive is a "lex specialis", whose provisions

\footnotetext{
$\overline{56}$ Walter and von Lewinkki (2010), para. 9.5.23.

${ }^{57}$ Case C-128/11 UsedSoft GmbH v. Oracle International Corp [2012] 3 CMLR 44.

${ }^{58}$ Ibid., at [22]-[27].

${ }^{59}$ Ibid., at [42].

${ }^{60} \mathrm{Ibid}$., at [44]-[47].
} 
are unaffected by the Infosoc Directive, as too simplistic. Admittedly, the CJEU conveniently held that the distinction of goods and services as the basis for exhaustion and non-exhaustion only applies to the Infosoc Directive, since the Software Directive makes no such distinction, indicating the intention of the EU lawmakers. ${ }^{62}$ Thus, cleared of the confusion caused by the distinction between goods and services, the CJEU was able to see the transaction for what it was and come to a reasonable conclusion. However, a more significant finding of the CJEU on the Infosoc Directive itself is that if there was a transfer of ownership of the copies, such transfer changes the act of communication under Art. 3 of the Infosoc Directive to an act of distribution under Art. 4 Infosoc Directive; if the provisions of Art. 4(2) are satisfied, then exhaustion could still occur. ${ }^{63}$ Instead of conflating all online transmission of copies of copyright works as a service in order to deny exhaustion, the CJEU took a more nuanced approach of examining the transaction for what it was. Indeed, the focus of the CJEU in determining whether a transfer of ownership had occurred was a clear finding on alienability. This finding on the alienability of the copy of the software downloaded by UsedSoft in effect enables the fulfilment of the property justification and the trade justification.

The Court also alluded to the argument that in case of online exhaustion it may not be possible to alienate the same copy of the work that was received by UsedSoft; instead UsedSoft would have to generate a new copy of the work. Under these circumstances, it is no longer only the issue of the right of distribution, but also the right of reproduction of the copyright owner which does not exhaust. Applying the exception to the reproduction right under Art. 5(1) of the Software Directive, the Court held that UsedSoft will not be required to obtain consent from the copyright owner to reproduce the software to enable him or her to use it. In effect, the CJEU held that the right of reproduction cannot be a hurdle to exhaustion occurring if all other requirements of exhaustion are satisfied. ${ }^{64}$

Although the UsedSoft decision is heavily criticised for its conception of exhaustion, it is fully explicable when one views it from the perspective of the Implied Licence Framework for Exhaustion. The CJEU's finding on the alienability of the copy of the software made it possible for the property and trade justifications to be fulfilled. With its finding that there was a contract of sale between the copyright owner and the copy owner, the CJEU effectively implied, based on Art. 4(2) of the Infosoc Directive, a licence driven by the property and the trade justifications, in favour of the copy owner, to reproduce the software to the limited extent of enabling UsedSoft to further distribute the software to third parties. Being a policy-based implied licence, the expressed terms of Oracle's agreement could not override the implied licence, given the significance of the policy reasons to EU law (free movement of goods); Oracle could not terminate the licence as it is not a consent-based implied licence; and the licence can be implied in favour of any

\footnotetext{
61 Ibid., at [49].

62 Ibid., at [54]-[58].

63 Ibid., at [51]-[52].

64 Ibid., at [79]-[83].
} 
subsequent purchaser if the circumstances triggered Art. 4(2) of the Infosoc Directive.

In principle, there is no reason why UsedSoft cannot apply in relation to other works of copyright. Recital 29 of the Infosoc Directive and Recital 33 of the Database Directive do prove to be a stumbling block. However, if these Recitals can be regarded only as a reflection of the prevailing circumstances at the time of enacting the directives which have now changed, their influence on the interpretation of the substantive provisions of the directive can be reduced. Further, the distinction between downloadable software and other works that can be downloaded cannot be justified for the purpose of exhaustion. If there is a discernible and permanent copy of any other work, such as an MP3 file of a song, merely because it is distributed online should not lead to a conclusion of non-exhaustion. It is important first to discern the conditions under which the copy was received from the copyright owner - whether as a transferee who has acquired the ownership of the copy, or a licensee whose enjoyment of the song is for a limited time.

\subsection{Authorisation Always Required for Services?}

As discussed above, having classified simplistically the exercise of certain rights as services, the provisions of the EU directives go on to provide that these rights do not exhaust. The directives state it as a natural consequence that the exercise of these rights will always require authorisation. As explained above, applying the Implied Licence Framework for Exhaustion, non-exhaustion of these rights only means that no licence may be implied in favour of the recipient of the copy based on property and trade justifications, permitting the recipient to exercise those rights. However, it does not necessarily follow that no licence may be implied under any circumstances. It may still be possible to imply a licence based on other policy reasons or other bases, such as consent. Therefore, non-exhaustion does not mean that authorisation is always required. Authorisation is only required if no licence can be implied at all, be it for the policy justifications that underlie exhaustion or otherwise.

This problem is more apparent in relation to the non-exhaustion of the right of communication and making available to the public. Article 3(3), read with Recital 29 of the Infosoc Directive, leads to a conclusion that every communication or making available of a work to the public will require authorisation. However, in interpreting the right of communication to the public, the CJEU has, in effect, ruled that only a communication made to a "new public" requires authorisation. ${ }^{65}$ Those who believe that, under Art. 3(3), every time a work is communicated, such communication must be authorised, argue that requiring authorisation only when the communication is addressed to a new public violates Art. 3(3). ${ }^{66}$

Admittedly, the concept of a new public is controversial. There are different ways of interpreting "new public", 67 and the one of relevance here is the interpretation based on the copyright owner's authorisation. ${ }^{68}$ In this sense, a new public means a public not taken into account by the copyright owner when authorising the initial communication. ${ }^{69}$ This means that by his or her initial communication the copyright owner only authorises those users who are within her contemplation, and not beyond. With the initial communication of the work, the 
copyright owner impliedly licenses the recipient of the initial communication to further communicate the work to those within the copyright owner's contemplation. The authorisation that supports initial communication also supports the further communication so long as the further communication is made to the same public initially authorised. In other words, the implied licence enjoyed by the recipient of the initial communication is based on the authorisation or consent of the copyright owner. It is clear that no policy justification is involved in determining how far the initial communication extends, but only the authorisation of the copyright owner based on what is within his or her contemplation. Thus, the concept of a new public incorporates a consent-based implied licence. That implied consent underlies the notion of new public has been confirmed by the CJEU in Soulier. ${ }^{70}$

It is evident from the Implied Licence Framework for Exhaustion that exhaustion is a policy-based licence implied based on the property and trade justifications, as discussed above. On the other hand, what underlies the concept of new public in the communication right is a consent-based implied licence (bare or contractual, depending on the circumstances). The stark contrast between these two scenarios cannot be overstated. Although in both cases an exclusive right of the copyright owner is consumed, it is consumed for altogether different reasons - the distribution right for reasons of policy and the communication right for reasons of consent. To equate what happens to the communication right due to the concept of new public with exhaustion is a gross misunderstanding of exhaustion. This is a stark example of the misconceptions that surround the concept of exhaustion as a general loss of right for whatever reason, and the generalised distinction between goods and services as the basis for exhaustion and non-exhaustion.

The narrative of a consent-based implied licence is by no means unique to the right of communication to the public. The rights that do not expressly exhaust, such as the rights of reproduction and adaptation, can also face consumption due to a consent-based implied licence. To explain this point further, one may consider the case of Blair $v$ Osborne, ${ }^{71}$ where the right of reproduction and adaptation were at issue. Here the claimant, an architect, was commissioned by the owner of a certain parcel of land to draw up architectural plans to build a house for a fee and to obtain planning permission. However, the contract said nothing about whether the claimant would retain copyright or assign the copyright to the land owner. The claimant drew up the plans, obtained planning permission and handed the plans over to the land owner for a fee. However, the land owner did not build the house, but instead sold

\footnotetext{
${ }^{65}$ C-306/05 SGAE v. Rafael Hoteles [2006] ECR I-11519 (SGAE); C-403/08 Football Association Premier League Ltd v. QC Leisure [2011] ECR I-9083 (FAPL); C-117/15 Reha Training v. GEMA [2016] 3 CMLR 40.

66 Hugenholtz and van Velze (2016), pp. 797, 810-11; ALAI (2014), p. 15; Rosati (2017), p. 1237.

67 McBride (2017). Here the author identifies two interpretations - the one based on the copyright owner's authorisation and the other based on the access provided by the alleged infringer's intervention.

68 The other interpretation is based on access, where a new public is the public to whom the copyright work was not accessible without the intervention of the defendant. This interpretation appears to have been adopted in Case C-466/12 Svensson v. Retriever Sverige AB [2014] WLR(D) 67 [31].

69 The interpretation adopted in SGAE, para. [40] and FAPL, para. [197].

70 Case C-301/15 Soulier v. Premier Ministre ECLI:EU:C:2016:878 at [36].
} 
the land to the defendant, who used the claimant's plans to build a house. ${ }^{72}$ The court held that the land owner as the person commissioning the work enjoyed an implied licence to reproduce and adapt the plan, since he had the consent of the claimant/copyright owner by virtue of commissioning. ${ }^{73}$ However, the further question was whether that implied licence extended to the defendant. The court held that the claimant's authorisation did extend to the defendant since it would have been within the contemplation of the claimant that the land may be sold. Thus, the initial act of authorisation in favour of the land owner to reproduce and adapt the architectural plans also extended to the purchaser of the land. Operationally, the consent-based implied licence in Blair $v$ Osborne is not different from the concept of new public. The question in both cases is - once the copyright owner provides her initial authorisation - the extent to which the authorisation extends. Thus, a consentbased implied licence can arise in relation to any exclusive right, and it should not be equated with exhaustion.

An example of a licence implied based on policy reasons other than those leading to exhaustion can be seen in the case of GS Media $v$ Sanoma Media ${ }^{74}$ In this case, certain copyright works had been uploaded to the internet without the consent of the copyright owner. A hyperlink to such content had been provided by the defendant. ${ }^{75}$ The question was whether providing a hyperlink to content that infringes copyright itself violates copyright as being an unauthorised exercise of the right of communication to the public. The court held that if the person providing the link knows of the infringing nature of the content, and is an entity pursuing profit, then it amounts to an infringement. The underlying reason was that the court recognised that the internet is of particular importance to the freedom of expression and information protected by Art. 11 of the Charter of Fundamental Rights. It further recognised that hyperlinks contribute to the sound operation of the internet and the exchange of opinions and information, given the immense amount of information available on the internet. ${ }^{76}$ These are clearly policy considerations driving the implication of a licence, given the obvious lack of consent on the part of the copyright owner when the work initially found its way to the internet. The merit of the decision in GS Media is highly contested. However, the methodology adopted by the court can be framed as implying a licence in favour of the person unknowingly linking to infringing content on the internet, permitting further communication of such content, based on the policy of protecting the right to freedom of expression and information. Although this is a policy-based implied licence, the policy is completely different from the policies driving exhaustion, and therefore cannot be equated with exhaustion.

The point being made is that the implied licence is a much broader doctrine than exhaustion. Explaining exhaustion within the implied licence framework reveals

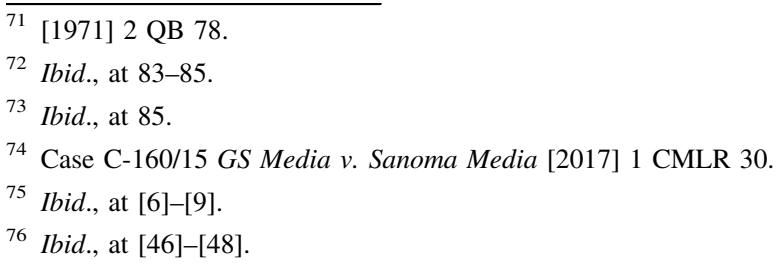


that there are other ways in which a licence may be implied that do not amount to exhaustion. Likewise, non-exhaustion is only the inability to imply a licence based on the policy reasons of property and trade justifications. Non-exhaustion does not take away the possibility of implying licences based on other policy reasons or on other bases, such as consent. Therefore, in any given situation, whether a person requires the authorisation of the copyright owner to exercise a right depends on whether there is a basis to imply any licence at all. Authorisation will be required if there is no basis for implying a licence, and not because a right does not exhaust.

\section{Conclusion}

Like any provision that reduces the intensity of protection granted to intellectual property, exhaustion is also highly contentious. In particular, exhaustion of a right in relation to the content on the internet is hotly debated. As we move towards a more complex engagement with copyright works on the internet, it becomes imperative that one understands what exhaustion is at its core.

Although exhaustion is understood in relation to the right of distribution caused by the first sale of a copy of a work, the general idea behind exhaustion is understood as the curtailment of a right. To drive home the point that exhaustion has a much more technical origin, this article examined the historical and jurisprudential origins of exhaustion. It demonstrated that the two distinct, but closely related policy reasons that underlie exhaustion are the property justification and the trade justification. Given that the concept of exhaustion focuses only on the copyright owner and her loss of a right, this article proposed the Implied Licence Framework for Exhaustion to capture not only the policies that drive exhaustion, but also its effect on the copy owner. This framework was then used to understand the concept of non-exhaustion.

Both exhaustion and non-exhaustion are products of their historical origin and are enshrined in the directives as sweeping generalisations. It so happened that the case law in which exhaustion occurred all concerned copies of the copyright work incorporated in a tangible medium. It also happened that non-exhaustion had arisen in the context of works incorporated in an intangible medium. This led to general principles in the EU directives that exhaustion can only occur in relation to goods and not in relation to services. This article applied the framework to show that there are more complex reasons why exhaustion does not occur in case of rights such as the rental right, re-utilisation of an online database and the right of communication and making available to the public. Merely labelling a right as a service fails to provide any clarity on why exhaustion does not take place.

The intention of the EU lawmakers may have been to simplify the law on exhaustion and non-exhaustion by adopting the distinction of goods and services. However, this simplification has only led to further misconceptions, namely that there is no digital exhaustion and that authorisation is always required whenever a service is offered. As regards digital exhaustion, this article argued that it is the nature of the copy of the work generated during the exercise of a right and the alienability of such copy that determine exhaustion, and not whether the copy is in 
tangible or intangible form. This article also argued that it is incorrect to state that the copyright owner's authorisation will always be required for the exercise of services. It showed in the wider context of implied licence that it is possible for the copyright owner to lose her rights for reasons other than those that drive exhaustion. A general understanding of exhaustion as any loss of right or that services do not exhaust is also unhelpful.

To dispel these misconceptions, this article therefore proposes that exhaustion be understood as a policy-based statutorily implied licence, with the policies being property justification and trade justification; any other loss of right should be understood based on the general doctrine of implied licence.

Open Access This article is distributed under the terms of the Creative Commons Attribution 4.0 International License (http://creativecommons.org/licenses/by/4.0/), which permits unrestricted use, distribution, and reproduction in any medium, provided you give appropriate credit to the original author(s) and the source, provide a link to the Creative Commons license, and indicate if changes were made.

\section{References}

ALAI (2014) Opinion on the criterion "new public", developed by the CJEU, put in the context of making available and communication to the public. 17 Sept 2014

Bently L, Sherman B (2014) Intellectual property law, 4th edn. OUP, Oxford

Bridge M (2014) The sale of goods, 3rd edn. OUP, Oxford

Bridge MG (2015) Personal property law. OUP, Oxford

Bridge MG, Gullifer L, McMeel G, Worthington S (2013) The law of personal property. Sweet \& Maxwell, Thomson Reuters, London

Davies G, Caddick N, Harbottle G (2016) Copinger and Skone James on Copyright, 17th edn. Sweet \& Maxwell, London

Hilty RM (2016) "Exhaustion" in the digital age. In: Calboli I, Lee E (eds) Research handbook on intellectual property exhaustion and parallel imports. Edward Elgar Publishing, Cheltenham

Honoré AM (1961) Ownership. In: Guest AG (ed) Oxford essays in jurisprudence. Clarendon Press, Oxford

Hugenholtz B, van Velze SC (2016) Communication to a new public? Three reasons why EU copyright law can do without a "new public". IIC p 797

McBride P (2017) The "new public" criterion after Svensson: the (ir)relevance of website terms and conditions. IPQ, p 262

McMeel G (2011) The construction of contracts - Interpretation, implication and rectification, 2nd edn. OUP, Oxford

Peden E (2000) Policy concerns behind implication of terms in law. LQR, p 459

Perzanowski A, Schultz JM (2016) The end of ownership: personal property in digital economy. MIT Press Scholarship Online, Massachusetts

Phillips J, Bently L (1999) Copyright issues: the mysteries of section 18. EIPR, p 133

Ricketson S, Ginsburg J (2006) International copyright and neighbouring rights: the Berne Convention and beyond, 2nd edn. OUP, Oxford

Rosati E (2017) GS Media and its implications for the construction of the right of communication to the public within EU copyright architecture. Common Mark Law Rev 54:1221

van Eechoud M (2009) Harmonizing European copyright law: the challenges of better lawmaking. Kluwer Law International, Alphen aan den Rijn

Walter MM, von Lewinski S (2010) European copyright law. OUP, Oxford 